\title{
Curativos e Úlcera Varicosa. O que deve saber o Flebólogo?
}

\author{
Rocha AG. ${ }^{1}$, Fernandes FA. ${ }^{1}$ \\ ${ }^{1}$ Pitangui - Brasil. \\ E-mail: linfagerais@gmail.com
}

Rocha A.G.; Fernandes F.A. 2013. Curativos e Úlcera Varicosa. O que deve saber o Flebólogo?, p.42. In: Bastos, Francisco Reis. Anais do V Simpósio Internacional de Flebologia [Blucher Medical Proceedings n.1 v.1]. São Paulo:

Blucher, 2014

http://dx.doi.org/10.5151/medpro-flebo-SIF_22
A insuficiência venosa apresenta como uma de suas complicações a ocorrência de ulceras dos membros inferiores. Há vários tratamentos cirúrgicos, clínicos, escleroterápicos e de contenção ao qual se somam os curativos e fatores de crescimento. O conhecimento das tecnologias existentes, disponíveis e de quando e como utilizar-se de cada uma é conhecimento fundamental para o flebólogo. Buscamos expor de forma sucinta as tecnologias disponíveis no mercado bem como a experiência que possuímos com cada uma das mesmas a nível hospitalar e ambulatorial. Lembro que como flebólogos temos a possibilidade de associar á escleroterapia, contenção, tratamento medicamentoso, fisioterápico e cirúrgico os curativos de alta tecnologia. Para tanto se faz necessário o conhecimento associado á pratica diária. Tal conhecimento nos propiciara podermos nos posicionar de forma técnica quando questionados sobre esta ou aquela tecnologia de curativos bem como utilizá-lo de forma adequada melhorando o processo de cicatrização e minorando os custos.

Palavras chave: escleroterapia, varizes, IVC, cicatrização, curativo. 